\title{
Analysis of Phenotypic Stability in 25 Cowpea Genotypes Across Six Environments
}

\author{
Tony Ngalamu ${ }^{1}$, Silvestro Kaka Meseka ${ }^{2}$, Beatrice Elohor Ifie ${ }^{1}$, Kwadwo Ofori ${ }^{1}$, John Saviour Yaw Eleblu* \\ Department of Crop Science, School of Agricultural Sciences, \\ College of Natural Resources and Environmental Studies, University of Juba, P.O. Box 82, Juba, South Sudan. \\ Received: 08-03-2019 \\ Accepted: 2-08-2019 \\ DOI: $10.18805 /$ IJARe.A-429
}

\section{ABSTRACT}

Twenty-five cowpea (Vigna unguiculata L.) genotypes were evaluated across six contrasting environments for phenotypic yield stability. Combined analysis of variance revealed significant differences among the genotypes and the main effects. $\mathrm{A} 1 \mathrm{~B} \times \mathrm{D}, \mathrm{BC} \times \mathrm{M}, \mathrm{L} 1 \mathrm{~B} \times \mathrm{M}, \mathrm{A} 1 \mathrm{~B} \times \mathrm{M}$, and $\mathrm{BA} \times \mathrm{I}$ were the best performing and stable genotypes. The non-parametric analysis showed that genotype IT93K-503-1 had the highest yield and BC $\times$ D had the lowest yield. Shukla stability analysis revealed Beledi A and Dan lla as the most stable across test environments and genotypes $\mathrm{A} 1 \mathrm{~B} \times \mathrm{D}, \mathrm{BC} \times \mathrm{M}$ and $\mathrm{BA} \times \mathrm{I}$ were good performers. The coefficient of variability graphical approach showed that genotypes $\mathrm{BC} \times \mathrm{I}, \mathrm{A} 1 \mathrm{~B} \times \mathrm{M}, \mathrm{A} 1 \mathrm{~B} \times \mathrm{D}$, Dan lla, $\mathrm{TA} \times \mathrm{M}$, Mouride, $\mathrm{L} 1 \mathrm{~B} \times \mathrm{I}, \mathrm{BC} \times \mathrm{M}$ and $\mathrm{L} 1 \mathrm{~B} \times \mathrm{D}$ were high yielding. This implies they would do well across the testing sites. However, genotype IT93K-503-1 should be promoted for cultivation in drought-prone environments.

Key words: Adaptability, Cowpea, Environment, Genotype, Stability, Yield.

\section{INTRODUCTION}

Agricultural drought stress is highly variable and unpredictable over seasons and years making it difficult to identify a representative environment that could be considered a drought stress condition. One of the main factors for variability in yield of cowpea genotypes across environments is the genotype and genotype by environment interaction (GEI) effects. Stability is an important aspect of breeding for drought tolerance. Since drought tolerance is polygenic, it is hard to select tolerant genotypes in droughtprone environments. This makes it important to conduct factor stability analyses in the selection of cowpea genotypes for release.

Plant breeders commonly use different stability analyses to investigate GEI effects. Firstly, Finlay and Wilkinson (1963) and Francis and Kannenberg (1978) approaches to measure the stability of genotypes over small environmental variability. Secondly, Plaisted (1960) and Shukla (1972) approaches suggest that a genotype is considered to be stable if its mean response in a trial is parallel to environmental response. Lastly, several authors (Eberhart and Russell, 1966; Lin and Binns, 1988, Kang and Gorman, 1989; Crossa, 1990) suggest that a genotype is considered stable if the error means square from the regression model on the environmental index is small. Kang (1988) reported that the most commonly used stability analysis is the rank sum which incorporates yield and stability. Another frequently used approach is the coefficient of variability (Francis and Kannenberg, 1978) which assesses both performance and stability of genotypes concurrently. This approach measures the overall performance and coefficient of variability (CV) for each genotype across environments. The mean yield is then plotted against the $\mathrm{CV}$. This approach was found to characterize genotypes into clusters rather than an estimate of stability per se. Use of approaches that give better stability estimates are crucial for selecting promising genotypes that combine high yield and stability which are most desired by farmers in the recent increase of frequent occurrence of drought in farmers' fields.

Ombakho and Tyagi (1987) reported that correlation coefficient analysis at times fails to reveal the true nature of the association between yield and its components. Thus, the use of path-coefficient analysis is a much better option. This method relays on the cause and effect situation among variables. It is a standardized partial regression coefficient and has a direct influence of one variable (independent) upon another (dependent).

Moisture deficit and flooding are major production constraints encountered in sub-Saharan Africa (SSA) over the seasons and years, between and within environments. Despite an increase in incidences of drought stress during the cropping season, cowpea has the ability to withstand drought stress better than other field crops. This study was designed to assess the effects of GEI and identified a sound and logical approach for identifying high yielding and stable genotypes.

\section{MATERIALS AND METHODS}

Field layout and genetic materials: Yield trial was carried out across six contrasting environments (drought stress and optimal conditions) in three locations Legon (Coastal Savanna) $5^{\circ} 38^{\prime} \mathrm{N}, 0^{\circ} 10^{\prime} \mathrm{E}$, Fumesua (Forest-Savanna)

\footnotetext{
*Corresponding author's e-mail: jeleblu@wacci.ug.edu.gh

${ }^{1}$ West Africa Centre for Crop Improvement, School of Agriculture, College of Basic and Applied Sciences, University of Ghana, PMB 30, Legon, Ghana. ${ }^{2}$ International Institute of Tropical Agriculture, PMB 5320, Oyo Road 200001, Ibadan, Nigeria.
} 
$6^{\circ} 41^{\prime} \mathrm{N}, 1^{\circ} 28^{\prime} \mathrm{W}$ and Nyankpala (Guinea Savanna), 9²4' $\mathrm{N}, 0^{\circ} 59^{\prime} \mathrm{W}$ ) in 2018 . The unfavourable conditions were due to drought-stress, whereas the optimum conditions occurred in well-watered experiments. The trial was planted in two adjacent blocks spaced $50 \mathrm{~m}$ apart denoting two water regimes. The first block (Block 1) was designated as wellwatered (WW) and the second (Block 2) as severe stress (SS). Plants planted in Block 2 were subjected to severe water stress-imposed by withdrawing irrigation water for three weeks at the flowering stage. Then watering was resumed for two weeks, twice a week, in order to score recovery and regrowth parameters of the genotypes. Twentyfive genotypes used in this study are $\mathrm{A} 1 \mathrm{~B} \times \mathrm{D} ; \mathrm{BC} \times \mathrm{D}, \mathrm{BC} \times \mathrm{I}$, BC $\times$ M, Beledi A, Beledi C, Dan lla, IT93K-503-1, L1B $\times$ D, L1B $\times$ I, L1B $\times$ M, A1B $\times$ I, Laduni 1B, Mouride, TA $\times$ D, TA $\times$ I, TA $\times$ M, Titinwa A, A1B $\times$ M, AGRAC-216, Apagu 1B, Asontem, $\mathrm{BA} \times \mathrm{D}, \mathrm{BA} \times \mathrm{I}$ and $\mathrm{BA} \times \mathrm{M}$. The genotypes were evaluated using $5 \times 5$ lattice square design with three replications. Each entry was planted in a two-row plot of $2 \mathrm{~m}$ spaced $0.6 \mathrm{~m}$ between rows and $0.20 \mathrm{~m}$ between hills within a row. All the recommended cultural practices were carried out to raise a good crop. Data were collected on an individual plant basis and means were computed.
Data analysis: Each water treatment and location were considered as an environment. Analyses of data combined across six environments were performed using GenStat $18^{\text {th }}$ Edition considering all effects as random except genotypes according to Vargas et al. (2013). Phenotypic stability was computed using GEA-R and coefficient of variability percent and seed yield graphical analysis. The path-coefficient analysis was carried out using SPSS $22^{\text {nd }}$ edition Statistical Software.

The combined analysis across environments was computed following the procedure of Vargas et al. (2013):

$$
Y_{i j k}=\mu+\operatorname{Rep}_{i}+\operatorname{Block}_{j}\left(\operatorname{Rep}_{i}\right)+\operatorname{Gen}_{k}+\operatorname{Cov}+\varepsilon_{i j k}
$$

where $Y_{i j k}$ is the trait of interest, $\mu$ is the mean effect, $\operatorname{Rep}_{i}$ is the effect of the $i$ th replicate, $\operatorname{Block}_{j}\left(\operatorname{Rep}_{i}\right)$ is the effect of the $j$ th incomplete block within the $i$ th replicate, $\mathrm{Gen}_{k}$ is the effect of the $k$ th genotype, Cov is the effect of the covariate and $\varepsilon_{i j k}$ is the error associated with the $i$ th replication, $j$ th incomplete block, and $k$ th genotype, which is assumed to be normally and independently distributed, with mean zero and homoscedastic variance $\sigma^{2}$. The $\mathrm{Si}^{(1)}$ and $\mathrm{Si}^{(2)}$ statistics are two rank stability approaches; $\mathrm{Si}^{(1)}$ statistic measures absolute rank difference of genotype over

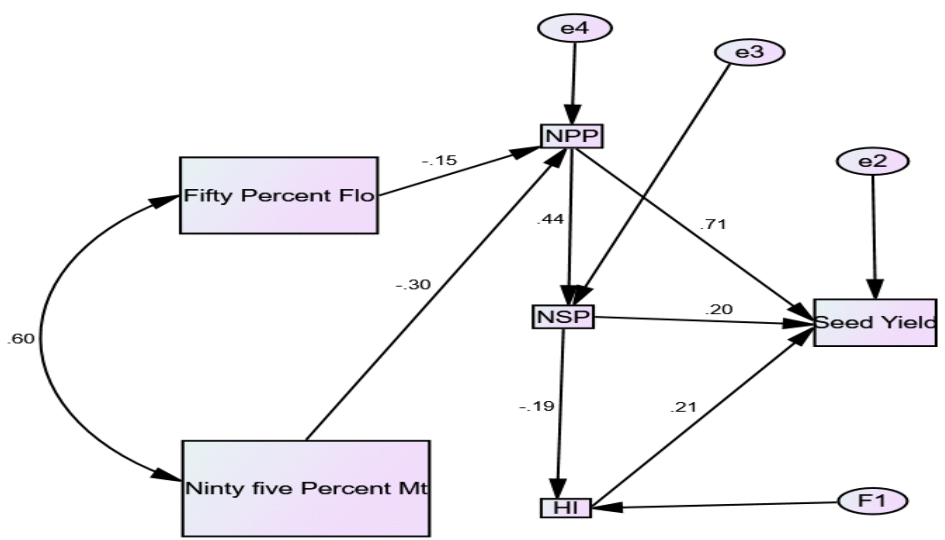

Fig 1: Path diagram of cause (traits studied) and effect (seed yield) relationship among 25 cowpea genotypes.

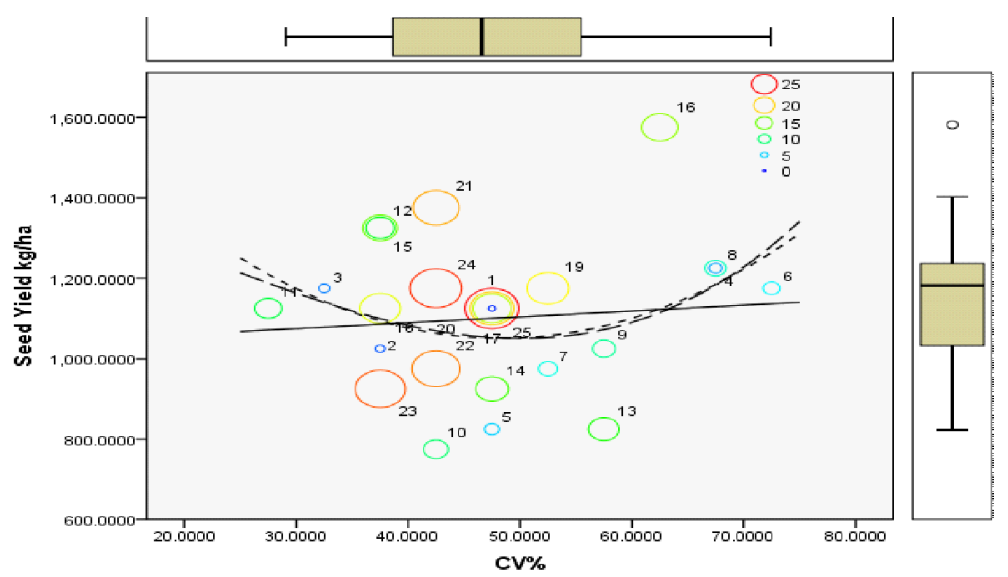

Fig 2: Cowpea seed yield vs CV percent of 25 genotypes across six environments.

GENOTYPES: Dan 1la (15), Asontem (6), AGRAC-216 (4), IT93K-503-1 (16), Mouride (21), BC $\times$ M (12), Beledi C (14), BC $\times \mathrm{D}(10), \mathrm{BA} \times \mathrm{I}(8)$, BA×D (7), Laduni 1B (12), Titinwa A (25), TAM (24), L1B $\times$ I (18), L1BM (19), L1BD (17), BAM (9), 1BCI (10), Beledi A (13), TA×D (22), Apagu $1 \mathrm{~B}(5), \mathrm{TA} \times \mathrm{I}(23), \mathrm{A} 1 \mathrm{~B} \times \mathrm{M}(3), \mathrm{A} 1 \mathrm{~B} \times \mathrm{D}(1)$ and $\mathrm{A} 1 \mathrm{~B} \times \mathrm{I}(2)$. 
environment, if $\mathrm{Si}^{(1)}=0$ for a genotype, then it shows maximum stability, whereas $\mathrm{Si}^{(2)}$ gives the variance between the ranks over environments, with zero variance being an indication of maximum stability. The exact variance and expectation of $\mathrm{Si}^{(1)}$ and $\mathrm{Si}^{(2)}$ were given by Huehn (1979).

\section{RESULTS AND DISCUSSION}

Combined analysis of variance: The combined analysis of variance across the six test environments revealed that genotypes and environments were significantly different. The main effect of genotype contributed $10.8 \%$ to the total variability and environment accounted for $63.8 \%$. The interaction between genotype and environment accounted for $25.4 \%$ of the total variation of the mean square (Table 1). This indicates both favourable and unfavourable conditions existed during the trial. The differential yield response to environments could be utilized to identify genotypes targeted to specific environments. Mean performance for seed yield

Table 1: Combined analysis of variance of seed yield $\left(\mathrm{kgha}^{-1}\right)$.

\begin{tabular}{lcc}
\hline Source of variation & DF & MS \\
\hline Geno & 24 & $607686^{* * *}$ \\
Env & 5 & $16418495^{* * *}$ \\
Geno $\times$ Env & 120 & $270609^{* * *}$ \\
Pooled Error & 294 & 129843 \\
Total & 449 & \\
\hline
\end{tabular}

$*, * *, * * *$ Significantly different at $0.05,0.01$ and 0.001 levels of probability, respectively. and some yield components is presented in Table 2. Genotype IT93K-503-1 had the highest seed yield $\left(1,526.1 \mathrm{~kg} \mathrm{ha}^{-1}\right)$ and $\mathrm{BC} \times \mathrm{D}$ had the lowest yield $\left(766.6 \mathrm{~kg} \mathrm{ha}^{-1}\right)$.

Path analysis: The number of days to $50 \%$ flowering and 95\% maturity are exogenous variables, and tend to negatively relate to the number of pods per plant as shown in the association between harvest index and the number of seeds per pod. It was observed that the harvest index was positively associated with seed yield as was the number of pods per plant with number of seeds per pod. The study also found that the number of seeds per pod and number of pods per plant had a positive influence on seed yield (Fig 1). Total positive association $(\mathrm{r}=0.91, \mathrm{P}<0.001)$ was observed for the number of pods per plant, number of seeds per pod, harvest index and seed yield. This suggests that an increment of a variable by a unit will significantly increase the seed yield. Thus, high seed yield could be obtained through selection for increased harvest index, number of pods per plant, number of seeds per pod. This result agrees with the study of dos Santos et al. (2014).

Yield stability analyses: Results of yield stability analyses using the sum rank method are presented in Table 3 . The genotypes with highest seed yield were IT93K-503-1, Mouride, $\mathrm{A} 1 \mathrm{~B} \times \mathrm{D}, \mathrm{BC} \times \mathrm{M}$ and $\mathrm{BA} \times \mathrm{I}$. Among these good performers, three are population developed for drought tolerance $(\mathrm{A} 1 \mathrm{~B} \times \mathrm{D}, \mathrm{BC} \times \mathrm{M}$ and $\mathrm{BA} \times \mathrm{I})$. Genotype superiority according to Lin and Binn (1988) revealed that IT93K-

Table 2: Mean yield of individual environments.

\begin{tabular}{|c|c|c|c|c|c|c|c|c|c|c|c|c|}
\hline \multirow[b]{2}{*}{ Geno } & \multicolumn{3}{|c|}{ Seed yield kg/ha } & \multicolumn{3}{|c|}{100 -seed weightNSP } & \multicolumn{2}{|c|}{ NSP } & \multicolumn{4}{|c|}{ NPP } \\
\hline & WW & DS & Mean & WW & DS & Mean & WW & DS & Mean & WW & DS & Mean \\
\hline Apagu 1B & 1007 & 685.6 & 1349.8 & 8.94 & 8.5 & 13.2 & 13.55 & 11.14 & 19.1 & 17.03 & 8.54 & 21.3 \\
\hline Laduni 1B & 1444 & 868.8 & 1878.4 & 11.13 & 11.85 & 17.1 & 14.66 & 11.69 & 20.5 & 19.37 & 7.6 & 23.2 \\
\hline Mouride & 1604 & 1078 & 2143.0 & 17.09 & 16.28 & 25.2 & 10.97 & 10.22 & 16.1 & 15.49 & 7.03 & 19.0 \\
\hline Beledi A & 1044 & 548 & 1318.0 & 10.09 & 10.07 & 15.1 & 12.09 & 10.87 & 17.5 & 17.9 & 5.26 & 20.5 \\
\hline Beledi C & 999 & 795.4 & 1396.7 & 8.21 & 8.89 & 12.7 & 11.45 & 10.72 & 16.8 & 20.69 & 8.72 & 25.1 \\
\hline Dan lla & 1435 & 1112.2 & 1991.1 & 17.33 & 16.64 & 25.7 & 11.3 & 10.86 & 16.7 & 16.41 & 6.97 & 19.9 \\
\hline IT93K-503-1 & 2232 & 876.5 & 2670.3 & 13.89 & 14.69 & 21.2 & 13.75 & 11.2 & 19.4 & 26.66 & 6.02 & 29.7 \\
\hline Titinwa A & 1487 & 774.7 & 1874.4 & 11.44 & 11.03 & 17.0 & 12.16 & 9.98 & 17.2 & 21.49 & 6.99 & 25.0 \\
\hline $\mathrm{A} 1 \mathrm{~B} \times \mathrm{D}$ & 1472 & 807.9 & 1876.0 & 9 & 7.61 & 12.8 & 11.94 & 10.86 & 17.4 & 17.01 & 8.39 & 21.2 \\
\hline $\mathrm{A} 1 \mathrm{~B} \times \mathrm{I}$ & 1068 & 826.9 & 1481.5 & 9.33 & 8.96 & 13.8 & 12.62 & 11.11 & 18.2 & 16.52 & 7.86 & 20.5 \\
\hline $\mathrm{A} 1 \mathrm{~B} \times \mathrm{M}$ & 1374 & 986.8 & 1867.4 & 12.11 & 11.44 & 17.8 & 12.13 & 10.79 & 17.5 & 16.81 & 6.97 & 20.3 \\
\hline $\mathrm{BA} \times \mathrm{D}$ & 1303 & 656 & 1631.0 & 9.52 & 8.76 & 13.9 & 12.19 & 10.89 & 17.6 & 19.06 & 6.54 & 22.3 \\
\hline $\mathrm{BA} \times \mathrm{I}$ & 1622 & 748.4 & 1996.2 & 11.41 & 11.11 & 17.0 & 11.81 & 11 & 17.3 & 20.44 & 5.79 & 23.3 \\
\hline $\mathrm{BA} \times \mathrm{M}$ & 1306 & 774.1 & 1693.1 & 10.97 & 10.16 & 16.1 & 11.76 & 10.42 & 17.0 & 20.37 & 5.17 & 23.0 \\
\hline $\mathrm{BC} \times \mathrm{D}$ & 940 & 556 & 1218.0 & 8.68 & 8.43 & 12.9 & 11.66 & 10.07 & 16.7 & 17.12 & 5.9 & 20.1 \\
\hline $\mathrm{BC} \times \mathrm{I}$ & 1202 & 1017.8 & 1710.9 & 10.6 & 9.94 & 15.6 & 10.98 & 10.68 & 16.3 & 20.03 & 8.05 & 24.1 \\
\hline $\mathrm{BC} \times \mathrm{M}$ & 1553 & 1062.7 & 2084.4 & 10.85 & 9.99 & 15.8 & 11.1 & 10.31 & 16.3 & 21.01 & 8.21 & 25.1 \\
\hline $\mathrm{L} 1 \mathrm{~B} \times \mathrm{D}$ & 1474 & 830.6 & 1889.3 & 11.09 & 10.5 & 16.3 & 13.51 & 11.46 & 19.2 & 17.73 & 6.9 & 21.2 \\
\hline $\mathrm{L} 1 \mathrm{~B} \times \mathrm{I}$ & 1365 & 955.1 & 1842.6 & 11.35 & 9.09 & 15.9 & 13.31 & 12.48 & 19.6 & 15.76 & 7.29 & 19.4 \\
\hline $\mathrm{L} 1 \mathrm{~B} \times \mathrm{M}$ & 1438 & 897.2 & 1886.6 & 11.67 & 11.04 & 17.2 & 13.24 & 11.55 & 19.0 & 16.74 & 6.58 & 20.0 \\
\hline $\mathrm{TA} \times \mathrm{D}$ & 1168 & 702.3 & 1519.2 & 11.82 & 10.66 & 17.2 & 11.43 & 9.55 & 16.2 & 15.52 & 6.76 & 18.9 \\
\hline $\mathrm{TA} \times \mathrm{I}$ & 976 & 800.5 & 1376.3 & 10.17 & 10.53 & 15.4 & 10.4 & 9.86 & 15.3 & 17.64 & 6.18 & 20.7 \\
\hline $\mathrm{TA} \times \mathrm{M}$ & 1304 & 895 & 1751.5 & 12.28 & 13.08 & 18.8 & 11.55 & 10.35 & 16.7 & 16.99 & 6.41 & 20.2 \\
\hline AGRAC-216 & 1521 & 963.4 & 2002.7 & 18.72 & 17.64 & 27.5 & 10.98 & 9.63 & 15.8 & 13.61 & 5.77 & 16.5 \\
\hline Asontem & 1554 & 874 & 1991.0 & 14.24 & 13.65 & 21.1 & 14.1 & 11.57 & 19.9 & 14.8 & 6.22 & 17.9 \\
\hline
\end{tabular}




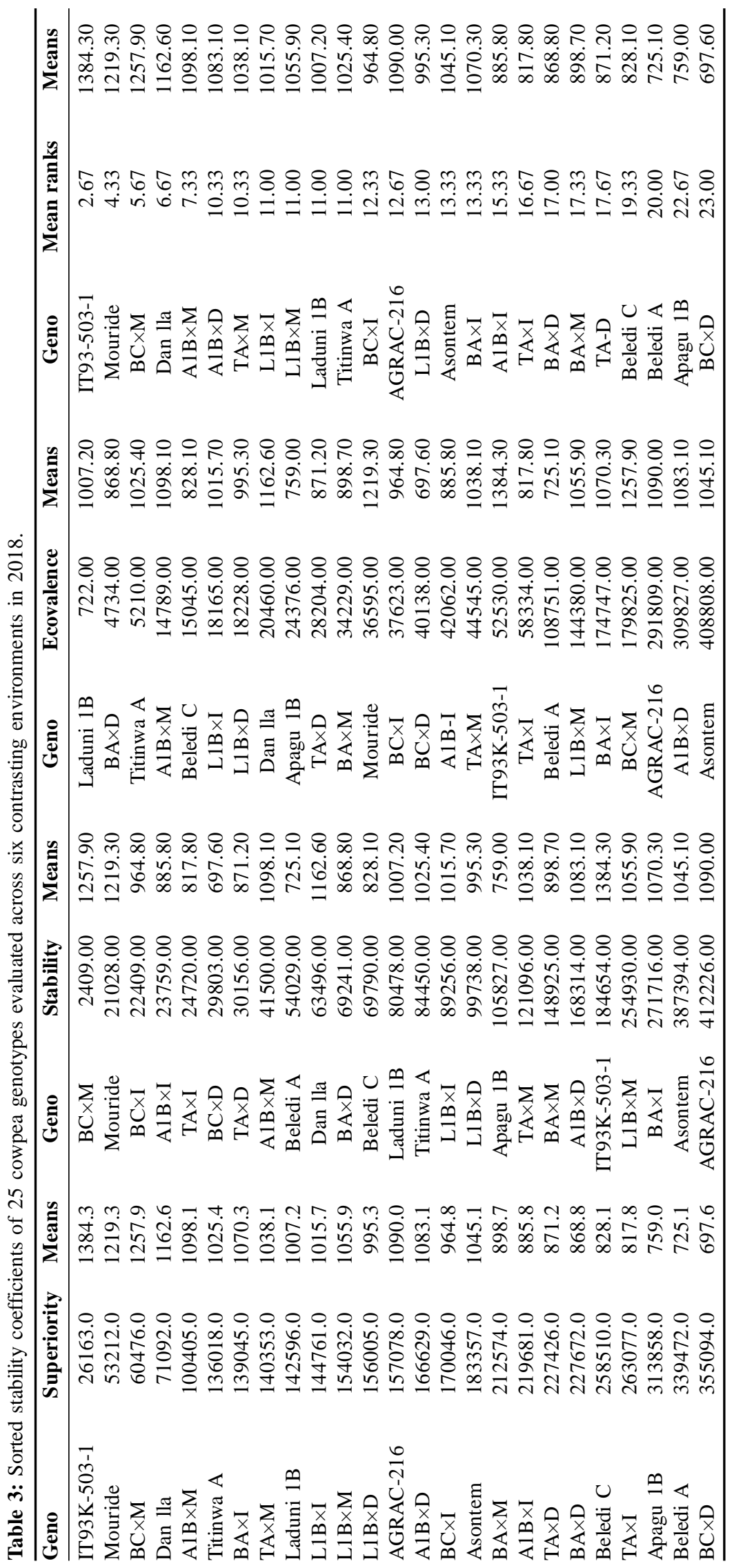


503-1, BC ×M, Dan lla, L1B ×I, Laduni 1B, Mouride, Titinwa $\mathrm{A}$ and A1BM were stable with high yields. The nonparametric analysis according to Nassar and Huehn (1987) revealed that IT93K-503-1 had the highest mean yield among the genotypes evaluated (Table 2). Vaezi et al. (2017) reported a similar trend when they used parametric and nonparametric measures for selecting stable and adapted barley genotypes.

The yield stability differences among the 25 cowpea genotypes were further assessed by using the graphical method (Francis and Kannenberg, 1978). The percent CV on the $\mathrm{x}$-axis was plotted against seed yield on the y-axis (Fig 2). The mean percent $\mathrm{CV}$ computed was $47.73 \%$. The cowpea genotypes with $\mathrm{CV}$ and seed yields above the grand mean were considered high yielding with low stability, whereas those with low $\mathrm{CV}$ percent and seed yields below the grand mean were considered highly stable and low yielding. Genotype IT93K-503-1 was found to be the highest yielding and $\mathrm{BC} \times \mathrm{D}$ was the lowest yielder. However, genotypes in the first quadrant as presented in (Fig 1), 11 (BC $\times \mathrm{I}), 3(\mathrm{~A} 1 \mathrm{~B} \times \mathrm{M}), 1(\mathrm{~A} 1 \mathrm{~B} \times \mathrm{D}), 13$ (Dan 1la), $24(\mathrm{TA} \times \mathrm{M})$,
21 (Mouride), $18(\mathrm{~L} 1 \mathrm{~B} \times \mathrm{I}), 12(\mathrm{BC} \times \mathrm{M})$ and $17(\mathrm{~L} 1 \mathrm{~B} \times \mathrm{D})$ yielded above the grand mean. This implies that they could thrive well across the testing sites under stress and optimal growing conditions.

\section{CONCLUSION}

Breeding cowpea for high yield, farmer preferred characteristics and broad adaptability should be the research focus for the cowpea improvement programme. Testing genotypes across environments and time will enable identification of stable and high yielding genotypes. In addition, this study found stability analysis to be a useful statistical tool for adaptability and selection of stable and high yielding genotypes. Our study revealed that when breeding for drought tolerance, breeders should consider other abiotic stresses including heat stress which, in most cases, occur simultaneously in farmers' fields.

\section{ACKNOWLEDGMENT}

This study is made possible by the scholarship awarded to the first author by Intra-ACP and DAAD for Doctoral Degree studies at West Africa Centre for Crop Improvement in the University of Ghana.

\section{REFERENCES}

Crossa, J. (1990). Statistical analyses of multilocation trials. Advances in Agronomy. 44: 55-85. https://doi.org/10.1016/S0065-2113 (08)60818.

dos Santos, A, Ceccon, G, Chamma, L.M..D, Martinho A. C and Batista V.A. (2014). Correlations and path analysis of yield components in cowpea. Crop Breeding and Applied Biotechnology. 14: 82-87.

Eberhart, S. A., and Russell, W. A. (1966). Stability parameters for comparing varieties. Crop Science. 6(1): 36-40. https://doi.org/ 10.2135/cropsci1966.0011183X000600010011x.

Finlay, K.W. and Wilkinson, G. N. (1963). The analysis of adaptation In A Plant-Breeding Programme The ability of some crop varieties to perform well over a wide range of environ-mental conditions has long been appreciated by the agronomist and plant breeder. In the cereal belts of southern Australia. Australian Journal of .Agricultural Research. 14: 742-754.

Francis, T. R. and Kannenberg, L.W. (1978). Yield stability studies in short-season maize: A descriptive method for grouping genotypes. Canadian Journal of Plant Science. 58 (4): 1029-1034.

Huehn, M. (1979). Contributions to the collection of phenotypic stability. I. proposal by some on based ranking information stability parameters. Computer Science in Medicine and Biology. 10: 112-117.

IBM Corp. Released (2013). IBM SPSS Statistics for Windows, Version 22.0. Armonk, NYIBM Corp.

Kang M.S. (1988). A rank method for selecting high yielding and stable crop genotypes. Cereal Research Communications.16:113-115.

Kang, M.S, and Gorman, D. P. (1989). Genotype $\times$ environment interaction in maize. Agronomy Journal. 8 (4):662-664.

Lin, C.S. and Binns, M. R. (1988). A superiority performance measure of cultivar performance for cultivar $\times$ location data.Canadian Journal of Plant Science. 68: 193-198.

Nassar, R, and Huehn, M. (1987). Studies on estimation of phenotypic stability: Test of significance for non-parametric measures of phenotypic stability. Biometrics. 43: 45-53.

Ombakho, G.A, and Tyagi, A.P. (1987). Correlation and path analyses for yield and its components in cowpea (Vigna unguiculata (L) Walp). East Africa Agriculture and Forest Journal. 53(1): 23-27.

Pacheco, Á, Vargas, M., Alvarado, G., Rodríguez, F., Crossa, J., Burgueño, J. (2015). GEA-R (Genotype x Environment Analysis with R for Windows) Version 4.1-, hdl:11529/10203, CIMMYT Research Data \& Software Repository Network, V16.

Plaisted R. L. (1960). A shorter method for evaluating the ability of selection to yield consistently over locations. American Potato Journal. 37:166-172.

Shukla, G. K. (1972). Some statistical aspect of portioning genotype and environmental components of variance. Heredity. 29: $237-245$.

Vaezi, B., Pour-Aboughadareh, A, Mehraban, A, Hossein-Pour, T, Rahmatolah Mohammadi, R, Armion M, and Dorri. M. (2017). The use of parametric and non- parametric measures for selecting stable and adapted barley lines. Archives of Agronomy and Soil Science. 64(5): 597-611. doi: 10.1080/03650340.2017.1369529

Vargas, M., Combs, E., Alvarado, G., Atlin, G., Mathews, K., Crossa, J. (2013). META: A suite of SAS programs to analyse multienvironment breeding trials. Agronomy Journal. 105: 11-19.

VSN International. (2015). GenStat for Windows $18^{\text {th }}$ Edition. VSN International Hemel Hempstead, UK. 